seleno-iso-chromanium bromide (II). This compound contains an asymmetric selenium atom. We have therefore converted it into the $d$-bromocamphorsulphonate, which on recrystallization from alcohol ultimately acquired a constant rotation, $[M] D-271^{\circ}$ in alcohol. This salt in turn was converted into the 2-p-chlorophenacyl-seleno-iso-chromanium picrate, which had $[M]_{D}-496^{\circ}$ in acetone solution, and into the corresponding mercuric tri-iodide, which had $[M]_{\mathrm{b893}}-535^{\circ}$, also in acetone solution.

The acetone solution of the picrate retained its activity unchanged when allowed to stand at $16^{\circ}$ for 20 hours, but underwent almost complete racemization when boiled for $1 \frac{1}{4} \mathrm{hr}$. The solution of the mercuric tri-iodide underwent very slow racemization even at room temperature.

It is noteworthy that a dissymmetric arsonium halide such as (I) can racemize only by partial dissociation to a tertiary arsine and alkyl halide, that is, by the establishment of a 'dissociation-equilibrium' of the type $[a b c d \mathrm{As}] \mathrm{Br} \rightleftarrows a b c \mathrm{As}+d \mathrm{Br}$. A dissymmetric selenonium halide such as (II) can, however, racemize either by the establishment of a similar equilibrium, $[a b c \mathrm{Se}] \mathrm{Br} \rightleftarrows a b \mathrm{Se}+c \mathrm{Br}$, or by direct racemization of the selenonium ion, that is, in compound (II), by direct oscillation of the $p$-chlorophenacyl radical above and below the plane of the ring. It is not unexpected, therefore, that the above selenonium picrate and mercuric tri-iodide are comparatively readily racemized.

The compound (II) is the second selenonium compound to be resolved into optically active forms : the first compound, methyl-phenyl-selenetine bromide, was resolved by Pope and Neville ${ }^{2}$, who obtained the corresponding dextro and loevo chloroplatinates having $[M]_{D}+55^{\circ}$ and $-54^{\circ}$ respectively.

We hope to resolve the sulphur and tellurium analogues of the compound (II), so that the rotatory dispersion of the three compounds can be compared.

F. G. MANN.

F. G. Holliman.

University Chemical Laboratory, Cambridge.

Nov. 17.

1 NATURE, 151, 474 (1943)

'J. Chem. Soc., 81, 1552 (1902).

\section{An Antibacterial Substance from Aspergillus clavatus and Penicillium claviforme and its Probable Identity with Patulin}

13. P. Wiesner, in a communication in NATURE ${ }^{1}$ in which he acknowledges the help and advice of Prof. H. Raistrick, Mr. George Smith and Dr. Harry Coke, reported the preparation from Aspergillus clavatus metabolism solutions of a concentrate possessing relatively high antibacterial activity. Similar active non-crystalline concentrates were obtained from the same fungus by S. A. Waksman et al. ${ }^{2}$ and investigated recently by H. W. Anderson ${ }^{3}$.

We have isolated the active constituent from the metabolism solution of a strain supplied to us by B. P. Wiesner as a crystalline entity, from which a number of well-characterized derivatives could be obtained. Whereas Waksman called his crude active principle 'clavacin', we had adopted the name 'clavatin'. In its pure form it has m.p. $109 \cdot 5-110 \cdot 5^{\circ} \mathrm{C}$. and forms a mono-acetyl derivative of $\mathrm{mp} .118-120^{\circ} \mathrm{C}$. Analysis and molecular weight determinations indicate an empirical formula $\mathrm{C}_{7} \mathrm{H}_{6} \mathrm{O}_{4}$ for clavatin.
E. Chain, H. W. Florey, and M. A. Jennings ${ }^{4}$ reported last year the isolation of a crystalline antibacterial substance from Penicillium claviforme, of m.p. $110^{\circ} \mathrm{C}$, for which they suggest the name 'claviformin'. We have prepared claviformin according to the above authors and established its identity with clavatin by the usual chemical methods.

In a publication by Raistrick et $a l . .^{6}$ the isolation and chemistry of patulin from Penicillium patulum Bainier is described. In view of the close similarity of physical, chemical and biological properties of patulin and clavatin and of their derivatives, tabulated below, it is highly probable that these two substances are identical.

Empirical formula

Melting point

Melting point of acetate

Melting point of $2: 4$-dinitrophenyl-hydrazone

Melting point of phenyl-hydra-

zone

Melting point of oxime

Melting point of methyl ether

tibacterial activity against

Staph. aureus

$\begin{array}{cc}\text { Clavatin } & \text { Patulin } \\ \mathrm{C}_{7} \mathrm{H}_{8} \mathrm{O}_{4} & \mathrm{C}_{7} \mathrm{H}_{8} \mathrm{O}_{4} \\ 109 \cdot 5-110 \cdot 5^{\circ} \mathrm{C} . & 111^{\circ} \mathrm{C} . \\ 118-120^{\circ} \mathrm{C} . & 118^{\circ} \mathrm{C} . \\ \text { Darkens without } & \text { Darkens without } \\ \text { melting } & \text { melting } \\ 149-150^{\circ} \mathrm{C} . & 152-153^{\circ} \mathrm{C} . \\ 152-155^{\circ} \mathrm{C} . & - \\ 69-70^{\circ} \mathrm{C} . & - \\ 1: 64,000-128,0001: 64,000-128,000\end{array}$

The identity is further supported by our evidence from analytical experiments, collected during the past year, many of the results duplicating the findings of Raistrick et al. We have also isolated a reductive degradation product of clavatin identified as $\beta$-propyl$\gamma$-butyrolactone. We have, however, obtained other experimental evidence, details of which we will publish elsewhere, which cannot yet be reconciled with the suggested structure for patulin.

Chemotherapeutic investigations have been carried out during the past year in association with Dr. F. C. Happold, Biochemical Laboratories, School of Medicine, University, Leeds. It is hoped that these results will be published in the near future.

\section{F. Bergel. R. KLein.}

A. L. Morrison. H. Rinderknecht. A. R. Moss. J. L. WARD.

Research Department,

Roche Products, Ltd.,

Welwyn Garden City. Nov. 30.

1 NATURE, 149, 357 (1942).

2 Science, 96, 202 (1942) and J. Bact., 45, 233 (1943).

Science, 98, 282 (1943).

'Brit. J. Exp. Path., 28, 202 (1942).

Lancet, ii, 625 (1943).

\section{Rate of Growth of Bracken}

For some considerable time, the widely held belief in the slow development of bracken plants and the initiation of the frond many months in advance of its expansion has been suspect. The idea of the old German morphologists ${ }^{1,2,3}$ of the unfolding of on frond and the growth of one internode of the frond. bearing rhizomes in a season does not fit in with the rapid rate of expansion of the plants seen in the field.

In order to test the rate of growth of individual plants, two young sporelings (each 2-3 in. across and bearing some five to six immature fronds) were put into a trough formed by slabs of concrete $3 \mathrm{ft}$. wide and $2 \mathrm{ft}$. deep, so arranged as to form a long, narrow, continuous trough some 4 in. across. This was filled with rich soil, so that the sporelings were put under optimum growth conditions. The sporelings were planted out on March 29, 1943, and left until October 11, 1943. 